Saudi Journal of Pathology and Microbiology

Abbreviated Key Title: Saudi J Pathol Microbiol

ISSN 2518-3362 (Print) |ISSN 2518-3370 (Online)

Scholars Middle East Publishers, Dubai, United Arab Emirates

Journal homepage: http://scholarsmepub.com/sjpm/

Original Research Article

\title{
Detection of Mycoplasma pneumoniae in Children with Respiratory Tract Infections by ELISA and PCR
}

Shantala Gowdara Basawarajappa ${ }^{1}$, Kusuma Gowdra Rangappa ${ }^{1}$, Ambica Rangaiah ${ }^{1}$, Rama Chaudhry ${ }^{2}$, Sathyanarayan Muthur Shankar ${ }^{1 *}$

${ }^{1}$ Department of Microbiology, Bangalore Medical College and Research Institute, Bengaluru, India

${ }^{2}$ Department of Microbiology, All India Institute of Medical Sciences, New Delhi, India

\author{
DOI: $10.36348 /$ SJPM.2019.v04i10.012 $\quad$ | Received: 21.10 .2019 | Accepted: 28.10 .2019 | Published: 30.10 .2019
}

*Corresponding author: Sathyanarayan Muthur Shankar

\section{Abstract}

Mycoplasma pneumoniae has been well established as a major cause of lower respiratory tract infections (LRTIs) accounting for $10-30 \%$ of all cases of community-acquired pneumonia and is clinically indistinguishable from other infectious causes of pneumonia. The study aimed to investigate the occurrence of $M$. pneumoniae as the etiologic pathogen in LRTIs among children and to compare Polymerase Chain Reaction [PCR] and serology for the diagnosis of M. pneumoniae in community-acquired LRTIs in children. A total of 133 children aged between 6 months and 12 years with signs and symptoms of community-acquired LRTIs attending the Paediatrics OPD, emergency or admitted to the wards of a tertiary care hospital were prospectively enrolled into the study. $M$. pneumoniae in throat swab samples was detected by conventional PCR, and compared with serology and clinical signs and symptoms. Univariate analyses was conducted to determine the association of $M$. pneumoniae infection among different categories of patients. 31 out of 133 patients included in the study $(23.3 \%)$ were positive for $M$. pneumoniae by any test. Among 31 patients, serology (IgM) was positive in 19 patients $(61.2 \%)$ and PCR in 12 patients $(38.7 \%) ; 2$ patients were found to be positive by both methods. Fever, cough, hurried breathing and intercostal retraction were the clinical signs and symptoms significantly associated with LRTIs due to $M$. pneumoniae $(P<0.05)$. A combination of clinical features, PCR and IgM for Mycoplasma pneumoniae is recommended depending upon the duration of illness for optimal diagnosis, timely initiation of therapy and to prevent overuse of macrolides.

Keywords: Community-acquired, Lower respiratory tract infections, Mycoplasma pneumoniae, Polymerase Chain Reaction, Serology, IgM ELISA.

Copyright @ 2019: This is an open-access article distributed under the terms of the Creative Commons Attribution license which permits unrestricted use, distribution, and reproduction in any medium for non-commercial use (NonCommercial, or CC-BY-NC) provided the original author and sources are credited.

\section{INTRODUCTION}

Lower respiratory tract infections (LRTIs) are a common cause of morbidity and mortality among young children worldwide, the overwhelming majority occurring in developing countries [1]. Mycoplasma pneumoniae has been well established as a major cause of LRTIs and accounts for 10-30 per cent of all cases of pneumonia [2]. M. pneumoniae is a small, cell walldeficient bacterium that is insensitive to $\beta$-lactam antibiotics and cannot be detected by Gram stain [3]. In the majority of cases of suspected $M$. pneumoniae pneumonia, the presumptive diagnosis is made on historic and clinical findings alone. Determining the aetiology is a challenge because some diagnostic tests of respiratory samples that are noninvasively obtained are insufficiently sensitive to identify the causative pathogens, while others are flawed, cumbersome, expensive, time consuming and technically difficult.
Other more reliable diagnostic procedures may place the patients at added risk of a complication or may require sophisticated methods not readily available in all clinical settings [4].

Because of the fastidious nature of the M.pneumoniae, culture methods are relatively insensitive, time consuming, expensive and are successful in only 30-60\% of the confirmed cases [5]. The cold agglutination test is an easy, rapid and sensitive $(50 \%)$ method; however, it lacks specificity $(50 \%)$. Commercially available Complement Fixation Test (CFT) and ELISA were believed to offer improved sensitivity and specificity [6]. However, the requirement for a second sampling and indeterminate time for seroconversion have proven to be major drawbacks [7]. Polymerase chain reaction (PCR) for amplification of specific short segments of nucleic acid sequence is a rapid and sensitive method to detect $M$. 
pneumoniae in respiratory samples and is promising with higher specificity and superior sensitivity up to $90 \%$ to that of culture or single point serology [8]. Limited literature is available on detection of $M$. pneumoniae in community acquired LRTI's using different diagnostic modalities in paediatric population in South India.

The present prospective study was undertaken to investigate the occurrence of M.pneumoniae in respiratory tract infections in children and to compare PCR and serology for the diagnosis of M.pneumoniae in community-acquired lower respiratory tract infections in children.

\section{MATERIALS AND METHODS Study Design}

This prospective, single centre study was conducted on community-acquired LRTIs in the Department of Microbiology, Bangalore Medical College \& Research Institute from November 2016 to October 2017.

A total of 133 children [with prevalence rate of $10 \%$ at 92 per cent confidence level the sample size would be $\sim 144(4 \mathrm{pq} / \mathrm{d} 2, \mathrm{p}=$ prevalence, $\mathrm{q}=100-\mathrm{p}$ and $\mathrm{d}=$ absolute error)] aged between 6 months and 12 years with signs and symptoms of community-acquired LRTIs attending paediatrics OPD, emergency or admitted to the wards of Vani Vilas Hospital, Bengaluru were prospectively enrolled into the study. The study protocol was approved by the Institutional Ethics Committee of Bangalore Medical College \& Research Institute, Bengaluru, India.

\section{Inclusion Criteria}

- Age between 6 months and 12 years,

- Presence of cough and fever with breathlessness of less than 30 days duration,

- Increased respiratory rate (with/without features of respiratory distress) on examination, and

- Presence of signs of consolidation/bronchospasm with/without wheeze on auscultation

\section{Exclusion Criteria}

- Hospital acquired pneumonia i.e. pneumonia that developed $72 \mathrm{~h}$ after hospitalization or within 7 days of discharge,

- $\quad$ Severe concomitant disease, and

From each patient a Throat swab was collected for PCR and 2-3 mL blood sample was collected in Clot Activator Tubes for serology. Throat swabs were placed in $2 \mathrm{~mL}$ viral transport medium (Hi-Media) and put in ice bag until taken to the laboratory for DNA extraction immediately or were stored at $-20^{\circ} \mathrm{C}$ for further processing. $[4,9,10]$

\section{Serology}

Serum was separated from the venous blood samples and stored at $-20^{\circ} \mathrm{C}$ [11]. IgM antibodies to M.pneumoniae was detected using the IgM ELISA kit (NOVALISA classic).The test was performed as per manufacturer's recommendations.

\section{PCR}

DNA extraction from throat swab was done using a QIAamp DNA mini kit (QIAGEN) according to the manufacturer's instructions.A 543 bp segment of the gene coding for of the P1 protein gene of M.pneumoniae was the target for amplification. The primers (Bangalore Genei Pvt. Ltd., Bengaluru, India) used were:

- Primer

5'CAAGCCAAACACGAGCTCCGGCC-3',

which is complimentary to the $P 1$ gene negative strand residues 3666-3688, and

- Primer2:

5'CCAGTGTCAGCTGTTTGTCCTTCCCC-3', which is complimentary to the $P l$ gene positive strand residues 4208-4183.

Amplification was done in $25 \mu \mathrm{l}$ reaction mixture containing 10-100 ng of genomic DNA, 10mM tris $\mathrm{HCl}(\mathrm{pH} 8.0), 15 \mathrm{mM} \mathrm{MgCl} 2,50 \mathrm{mM} \mathrm{KCl}, 200 \mu \mathrm{m}$ of each dntp, $5 \mathrm{pM}$ of each oligonucleotide primer and $0.5 \mu \mathrm{L}$ of Taq DNA polymerase (Bangalore Genei Pvt. Ltd., Bengaluru, India) using a thermal cycler . PCR amplification consisted of 35 cycles. Initial DNA denaturation was at $94^{\circ} \mathrm{C}$ for $30 \mathrm{sec}$, annealing at $55^{\circ} \mathrm{C}$ for $30 \mathrm{sec}$ and extension at $72^{\circ} \mathrm{C}$ for $30 \mathrm{sec}$. Final extention at $72^{\circ} \mathrm{C}$ was allowed for $5 \mathrm{~min}$. Amplified PCR products was subjected to electrophoresis on ethidium bromide stained agarose gel, along with a molecular weight marker. A band at 543 bp was considered to be a positive result [4]. Mycoplasma pneumoniae p1 gene cloned in vector pGEM-T (543 bp) was used as the positive control in the study.

\section{RESULTS}

A total of 133 children were enrolled in this study, out of which 67 were females and 66 were males.

Demographic profile: The age of the patients in the study group ranged from 6 months to 12 years. The maximum number of cases were found in $<5$ years age group (Figure-1). There was no statistically significant association between the age of the patients and the incidence of $M$. pneumoniae infection $(P>0.05)$. Of the total 31 patients positive for $M$. pneumoniae by any test (serology and PCR), $20(64.5 \%)$ were males and $11(35.48 \%)$ females. There was no significant association between the sex of the patient and the incidence of $M$. pneumoniae ( $P>0.05)$ (Table-1). 


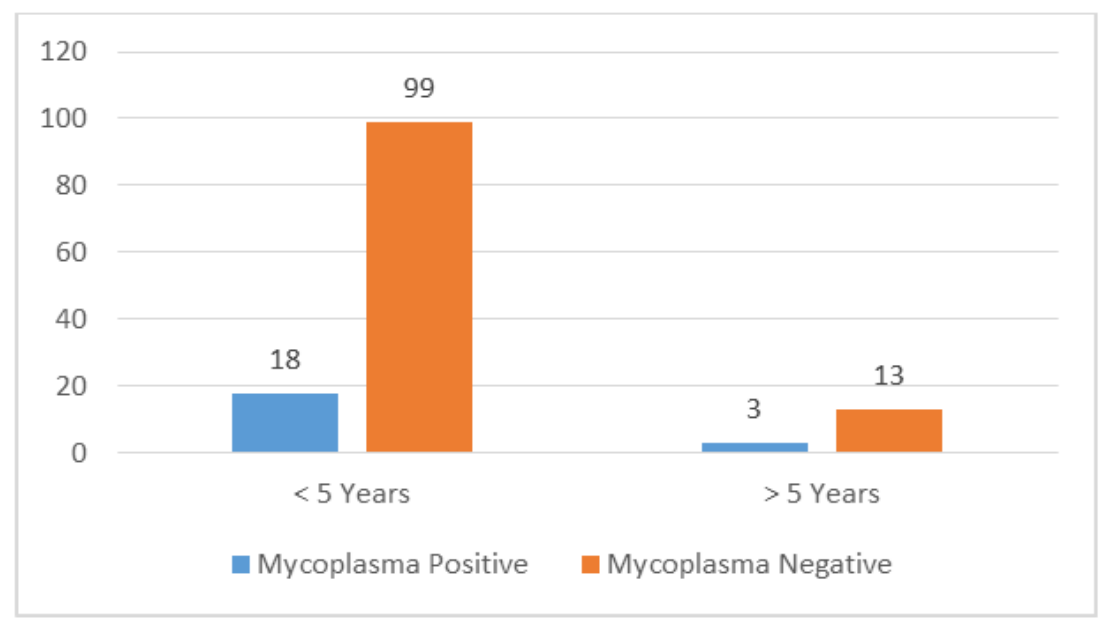

Fig-1: Age distribution of cases

Table-1: Association of M. pneumoniae with age, sex, symptoms and signs

\begin{tabular}{|c|c|c|c|c|c|c|c|}
\hline \multicolumn{2}{|c|}{ Character } & M Pos $(\mathbf{n = 3 1})$ & $\mathbf{\%}$ & $\mathbf{M}$ Neg $(\mathbf{n = 1 0 2})$ & $\mathbf{\%}$ & Chi Square & p Value \\
\hline \multirow{2}{*}{ Sex } & Male & 20 & 64.52 & 46 & 45.10 & 2.85 & 0.0914 \\
\cline { 2 - 8 } & Female & 11 & 35.48 & 56 & 54.90 & 2.85 & 0.0914 \\
\hline \multirow{2}{*}{ Age } & $<5$ Years & 28 & 90.32 & 89 & 97.06 & 1.18 & 0.2774 \\
\cline { 2 - 8 } & $>$ 5 Years & 3 & 9.68 & 13 & 12.75 & 0.02 & 0.8875 \\
\hline Fever & 14 & 45.16 & 81 & 79.41 & 12.04 & 0.0005 \\
\hline Cough & 11 & 35.48 & 90 & 88.24 & 33.8 & $<0.001$ \\
\hline Rhinorrhoea & 5 & 16.13 & 20 & 19.61 & 0.03 & 0.8625 \\
\hline Noisy breathing & 1 & 3.23 & 4 & 3.92 & 0.13 & 0.7184 \\
\hline Hurried breathing & 6 & 19.35 & 58 & 56.86 & 11.94 & 0.0005 \\
\hline Chest pain & 1 & 3.23 & 1 & 0.98 & 0 & 1 \\
\hline Vomiting & 2 & 6.45 & 5 & 4.90 & 0.01 & 0.9203 \\
\hline Abdominal pain & 1 & 3.23 & 1 & 0.98 & 0 & 1 \\
\hline Altered sensorium & 2 & 6.45 & 2 & 1.96 & 0.46 & 0.4976 \\
\hline Crepitation & 6 & 19.35 & 9 & 8.82 & 1.69 & 0.1936 \\
\hline Subcostal retraction & 6 & 19.35 & 8 & 7.84 & 2.23 & 0.1354 \\
\hline Intercostal retraction & 6 & 19.35 & 2 & 1.96 & 9.83 & 0.0017 \\
\hline Rhonchi & 0 & 0.00 & 5 & 4.90 & 0.51 & 0.4751 \\
\hline
\end{tabular}

Clinical signs and symptoms: The comparison of clinical data of LRTI patients diagnosed for $M$. pneumoniae based on PCR assay and serology, revealed that fever, cough and hurried breathing were the commonest symptoms in both the groups. The clinical signs and symptoms for $M$. pneumoniae positive and $M$. pneumoniae negative patients did not show any significant difference $(P>0.05)$. Of the predominant symptoms, only the presence of fever, cough and hurried breathing were significantly associated with LRTIs due to $M$. pneumoniae $(P<0.05)$. Physical examination most commonly revealed scattered crepitations, subcostal and intercostal retractions.
Except for the presence of intercostal retractions $(P<0.05)$, none of the other signs was found to be significantly associated with the incidence of $M$. pneumoniae (Table-1).

Microbiological Profile: Out of 133 patients, 31 patients $(23.3 \%)$ were positive for $M$. pneumoniae by any test (serology and PCR) (Table-2). Among 31 patients, serology $(\operatorname{IgM})$ in 19 patients $(61.2 \%)$ and PCR in 12 patients $(38.7 \%$ ) (Figure-2), when combinations of serology and PCR were considered two patients were found to be positive for IgM and PCR.

Table-2: Diagnostic efficacy of IgM ELISA and PCR

\begin{tabular}{|c|c|c|c|}
\hline Diagnostic test performed & $\begin{array}{c}\text { Study group } \\
(\mathbf{n = 1 3 3 )} \mathbf{n}(\boldsymbol{\%})\end{array}$ & $\begin{array}{c}\text { Positive cases } \\
(\mathbf{n = 3 1}) \mathbf{n}(\boldsymbol{\mathbf { \% }})\end{array}$ & \multirow{2}{*}{ p- Value } \\
\hline IgM ELISA & $19 / 133(14.28)$ & $19 / 31(61.29)$ & \multirow{2}{*}{0.18024} \\
\hline PCR & $12 / 133(9.02)$ & $12 / 31(38.70)$ & \\
\hline
\end{tabular}




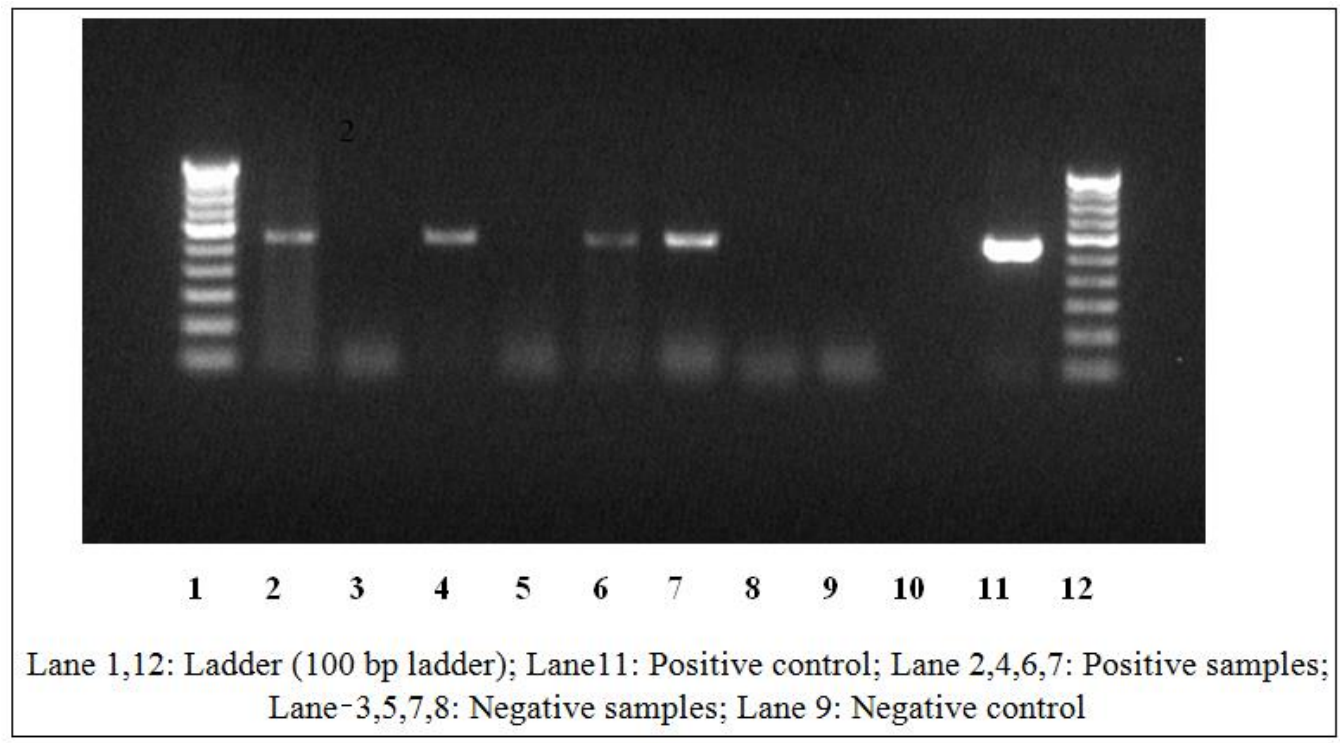

Fig-2: Gel electrophoresis of polymerase chain reaction amplification products for Mycoplasma pneumoniae P1 gene of 543 bp

\section{DISCUSSION}

Respiratory tract infections caused by Mycoplasma pneumoniae in children often go undiagnosed as they are clinically indistinguishable from viral pneumonia. There is no single test that reliably and rapidly detects Mycoplasma pneumonia. The treatment is empirical as defined in practice Guidelines for management of CAP. Earlier serology formed the main stay of diagnosis. Diagnosis by serological tests lack specificity, require paired samples, positive after 7 days of illness. Culture of Mycoplasma pneumoniae is laborious, time consuming and requires expertise. Molecular tests like PCR help in early diagnosis and can be used for diagnosis [12].

The present study was undertaken to detect $M$. pneumoniae infection in children with communityacquired LRTIs. About $90.32 \%$ cases belonged to age group $<5$ years and this age group also had a maximum number of positive cases which is in agreement with the epidemiological data based on serological studies $[4$, 13]. Comparison of clinical signs and symptoms between $M$. pneumoniae-infected and non-infected patients revealed that fever, cough, hurried breathing, with signs of crepitations, intercostal and subcostal retractions were predominant findings in $M$. pneumoniae-positive patients (Table 1) and are comparable with findings of Chaudhry R et al., [14]

Using a combination of PCR and serology, overall 31 of 133 patients included in the present study (23.3\%) were found positive and the results are comparable with prevalence rate of $10-30 \%$ reported in different studies [14-16]. In the present study, maximum samples were positive by serology followed by PCR. IgM antibody was positive in 19(14.28\%) out of 133 children with suspected Mycoplasma pneumoniae LRTI which was in concordance to study done by Kashyap B et al., [4]. They found serological evidence of Mycoplasma pneumoniae in 15 (20\%) out of 75 children based on ELISA for IgM antibodies. In the study by Kumar P et al., IgM antibody was positive in $20(23.9 \%)$ out of 86 children with suspected Mycoplasma pneumoniae LRTI [16].

PCR was positive in $12(9.022 \%)$ of 133 clinically suspected cases in the present study. Kashyap B. et al have reported presence of $M$. pneumoniae DNA in the nasopharyngeal aspirates of $13(17.33 \%)$ of the total 75 patients studied. [4] Dash et al in their study have reported 5 out of 130 cases (4\%) studied to be positive by PCR. [2]

Low positivity of PCR in our study could be attributed to:

- Presence of PCR inhibitors in samples that can lead to false-negative results;

- Stage of sampling influences results and the diagnostic accuracy of PCR may decrease at $\geq 7$ days after onset of disease in contrast to serology.

- Acquiring appropriate samples for PCR is relatively difficult in children [17-19].

In the present study, serology was positive in only 2 of the 12 PCR positive cases. Therefore, sensitivity and specificity of PCR compared to serological assay (ELISA) was $16.6 \%$ and $83.33 \%$ per cent, respectively (Table-3). Thurman et al., also showed that the sensitivity of the PCR assay reduces with the delay in collection of samples from the onset of the disease [20]. However, the proportion of positive test detection by two test was found to be similar when the Chi-square test $(p>0.05)$ was applied (Table-2). The limitation of the study was that paired sample testing for IgM ELISA was not done to demonstrate rise in titre of antibodies. 
Table-3: ELISA and PCR results for M. pneumoniae

\begin{tabular}{|c|c|c|c|}
\hline \multirow{2}{*}{ IgM ELISA } & \multicolumn{2}{|c|}{ PCR } & \multirow{2}{*}{ Total (\%) } \\
\cline { 2 - 3 } & Positive & Negative & \\
\hline Positive & $2(16.6 \%)$ & $17(14.2 \%)$ & $19(14.5 \%)$ \\
\hline Negative & $12(83.3 \%)$ & $102(85.71)$ & $114(85.6 \%)$ \\
\hline & $14(100 \%)$ & $119(100 \%)$ & $133(100 \%)$ \\
\hline
\end{tabular}

A review and meta-analysis by Zhang et al., highlights the significant role of PCR in diagnosis of $M$. pneumoniae infections, while emphasizing that serology remains the mainstay of diagnosis as it is relatively inexpensive and can be performed in routine labs. In view of these, the authors recommended a combination of serology and PCR to provide rapid, reliable and accurate diagnosis of $M$. pneumoniae infections [19].

\section{CONCLUSION}

The occurrence of Mycoplasma pneumoniae among respiratory tract infections in children was $23.3 \%$ in the present study, and majority of them were noted in children $<5$ years of age. The authors recommend a combination of clinical features, IgM antibody detection and Polymerase Chain Reaction for Mycoplasma pneumoniae for optimal diagnosis, timely initiation of therapy and in order to prevent overuse of macrolides, depending upon the duration of illness in suspected lower respiratory infections in children.

\section{ACKNOWLEDGEMENTS}

The authors express sincere gratitude to Rajiv Gandhi University of Health Sciences, Karnataka for funding the research project and Ms. Shaheen Taj for technical assistance during the course of the project.

\section{REFERENCES}

1. Forgie, I. M., O'Neill, K. P., Lloyd-Evans, N., Leinonen, M., Campbell, H., Whittle, H. C., \& Greenwood, B. M. (1991). Etiology of acute lower respiratory tract infections in Gambian children: I. Acute lower respiratory tract infections in infants presenting at the hospital. The Pediatric infectious disease journal, 10(1), 33-41.

2. Dash, S., Chaudhry, R., Dhawan, B., Dey, A. B., Kabra, S. K., \& Das, B. K. (2018). Clinical spectrum and diagnostic yields of Mycoplasma pneumoniae as a causative agent of communityacquired pneumonia. Journal of laboratory physicians, 10(1), 44-49.

3. Waites, K. B., \& Talkington, D. F. (2004). Mycoplasma pneumoniae and its role as a human pathogen. Clinical microbiology reviews, 17(4), 697-728.

4. Kashyap, B., Kumar, S., Sethi, G. R., Das, B. C., \& Saigal, S. R. (2008). Comparison of PCR, culture $\&$ serological tests for the diagnosis of Mycoplasma pneumoniae in community-acquired lower respiratory tract infections in children. Indian Journal of Medical Research, 128(2), 134.
5. Tully, J. G., Rose, D. L., Whitcomb, R. F., \& Wenzel, R. P. (1979). Enhanced isolation of Mycoplasma pneumoniae from throat washings with a newly modified culture medium. Journal of Infectious Diseases, 139(4), 478-482.

6. Beersma, M. F., Dirven, K., van Dam, A. P., Templeton, K. E., Claas, E. C., \& Goossens, H. (2005). Evaluation of 12 commercial tests and the complement fixation test for Mycoplasma pneumoniae-specific immunoglobulin $\mathrm{G}$ (IgG) and IgM antibodies, with PCR used as the "gold standard”. Journal of Clinical Microbiology, 43(5), 2277-2285.

7. Jacobs, E. (1993). Serological diagnosis of Mycoplasma pneumoniae infections: a critical review of current procedures. Clinical Infectious Diseases, 17(Supplement_1), S79-S82.

8. Waris, M. E., Toikka, P., Saarinen, T., Nikkari, S., Meurman, O., Vainionpää, R., ... \& Ruuskanen, O. (1998). Diagnosis of Mycoplasma pneumoniaepneumonia in children. Journal of clinical microbiology, 36(11), 3155-3159.

9. Zaki, M. E. S., Raafat, D., \& Metaal, A. A. E. (2009). Relevance of serology for Mycoplasma pneumoniae diagnosis compared with PCR and culture in acute exacerbation of bronchial asthma. American journal of clinical pathology, 131(1), 74-80.

10. World Health Organisation, UNICEF. (2005). Integrated management of neonatal and childhood illness. New Delhi Ministry of Health and Family Welfare, Government of India, New Delhi.

11. Myers, R. M., \& Koshi, G. (1982). Agglutination tests for serodiagnosis of febrile illnesses. In: Diagnostic Procedures in Medical Microbiology and Immunology/Serology. Christian Medical College and Hospital, Vellore, India. Concordia Press, 137143.

12. Bartlett, J. G., Dowell, S. F., Mandell, L. A., File Jr, T. M., Musher, D. M., \& Fine, M. J. (2000). Practice guidelines for the management of community-acquired pneumonia in adults. Clinical infectious diseases, 31(2), 347-382.

13. Kumar, S., Garg, I. B., Sethi, G. R., Kumar, S., \& Saigal, S. R. (2018). Detection of immunoglobulin $M$ and immunoglobulin $G$ antibodies to Mycoplasma pneumoniae in children with community-acquired lower respiratory tract infections. Indian Journal of Pathology and Microbiology, 61(2), 214-218.

14. Chaudhry, R., Sharma, S., Javed, S., Passi, K., Dey, A. B., \& Malhotra, P. (2013). Molecular detection of Mycoplasma pneumoniae by quantitative real-time PCR in patients with community acquired pneumonia. Indian $\mathrm{J}$ Med Res, 138(2), 244-251.

15. Cherian, C. S., Nair, T. S., Bai, S. S., \& Oommen, S. (2016). Prevalence and clinical profile of mycoplasma pneumoniae respiratory infection in 
children: a hospital based study. International Journal Contemp Pediatr, 3(2), 612-615.

16. Kumar, P., Patil, A. T., \& Latha, F. J. (2016). A study of prevalence of Mycoplasma pneumoniae pneumonia and validation of Immunoglobulin $\mathbf{M}$ for Mycoplasma pneumoniae in the diagnosis of Mycoplasma pneumoniae pneumonia. Indian Journal Child Health, 3(1), 32-35.

17. Tjhie, J. H., Van Kuppeveld, F. J., Roosendaal, R., Melchers, W. J., Gordijn, R., MacLaren, D. M., ... \& Van Den Brule, A. J. (1994). Direct PCR enables detection of Mycoplasma pneumoniae in patients with respiratory tract infections. Journal of clinical microbiology, 32(1), 11-16.

18. Nilsson, A. C., Björkman, P., \& Persson, K. (2008). Polymerase chain reaction is superior to serology for the diagnosis of acute Mycoplasma pneumoniae infection and reveals a high rate of persistent infection. BMC microbiology, 8(1), 93.

19. Zhang, L., Zong, Z. Y., Liu, Y. B., Ye, H., \& Lv, X. J. (2011). PCR versus serology for diagnosing Mycoplasma pneumoniae infection: a systematic review \& meta-analysis. The Indian journal of medical research, 134(3), 270-280.

20. Thurman, K. A., Walter, N. D., Schwartz, S. B., Mitchell, S. L., Dillon, M. T., Baughman, A. L., ... \& Winchell, J. M. (2009). Comparison of laboratory diagnostic procedures for detection of Mycoplasma pneumoniae in community outbreaks. Clinical Infectious Diseases, 48(9), 1244-1249. 